Revista Iberoamericana, Vol. LXIX, Núm. 205, Octubre-Diciembre 2003, 985-999

\title{
NEGOCIACIONES QUEER EN FRESA Y CHOCOLATE: IDEOLOGÍA Y HOMOEROTISMO
}

\author{
POR \\ David William Foster \\ Arizona State University
}

No importa qué asuntos se traten respecto a la película Fresa y chocolate (1993) de Tomás Gutiérrez Alea, es fundamental considerar una pregunta dominante: ¿por qué David y Diego nunca cogen? Este asunto nunca se pregunta directamente en la película y, consecuentemente, nunca se responde. Además, mucho del comentario crítico (característico de las críticas de la película y su relación con los parámetros socio-históricos de la industria del filme posrevolucionario en Cuba) enfoca la relación entre estos dos hombres como un paradigma en la sociedad cubana para la "tolerancia" a la diferencia, la diferencia sexual, específicamente, pero la diferencia individual en general, en el contexto de la lucha en Cuba para afirmar los valores institucionales y personales que no imponen como imperativa la necesidad de que el ciudadano/individuo se ajuste a un esquema rígido de conducta social. La higiene sexual fue una de las preocupaciones originales de la reestructuración posrevolucionaria de la sociedad cubana: más específicamente, la prostitución como una señal de la explotación capitalista, la homosexualidad como una señal de decadencia burguesa, y un estándar inadecuado de la vida de la familia como una señal de un compromiso enajenado con la reproducción apropiada del "nuevo cubano". Inevitablemente allí surgieron ideologías conflictivas respecto a la sexualidad antes de la revolución, la sexualidad como defendían varias vertientes de la revolución, y la sexualidad como se podría definir en contraste con paradigmas alternativos que surgen de la interacción de la sociedad cubana posrevolucionaria con un conjunto muy diverso de aliados.

A pesar de que dejaré que otros muestren en detalle la influencia de la posmodernidad en Cuba a través de sus interacciones con otros países como Argentina, México, Brasil y España, el hecho de que Fresa y chocolate apunte hacia la apertura de un debate respecto a la naturalización de las relaciones entre personas del mismo sexo a mediados de los noventa en Cuba solo puede ser una influencia de estas (y otras) sociedades, todas las cuales han visto cambios enormes en las últimas dos décadas respecto a las relaciones entre personas del mismo sexo y a las actitudes institucionales, colectivas y personales hacia éstas. ${ }^{1}$ Es una pregunta abierta considerar hasta qué punto alguna de estas sociedades (con la posible excepción de España en el presente momento) puede ser considerada amigable

${ }^{1}$ Sobre la homosexualidad en Cuba, véanse Lumsden, Leiner, Behar; sobre la ideología liberacionista del filme, véanse Serna Servín, Bejel. 
con los gays. No parece ser el caso de Cuba, a pesar de que hoy ya no hay el imperativo de perseguir el comercio del sexo para defender el beneficio económico del turismo internacional en Cuba, lo cual ha traído consigo un relajamiento en las normas revolucionarias respecto a otras manifestaciones de la sexualidad: la higiene sexual no puede ser un asunto esencial en la sociedad cubana a comienzos del nuevo siglo (la publicación en Cuba de la defensa de Felipe de J. Pérez de la homosexualidad es un notable acontecimiento).

Es difícil saber si esto significa que Cuba ha entrado en un período de sexualidad posmoderna (la lesbigay, la queer), período que permite la recuperación de la zona ambigua de la homosocialidad que termina siendo homosexualidad (el código mediterráneo antiguo en el cual el maricón es una figura crucial, una figura en la cual las relaciones del mismo sexo también ocurren, pero sin poder llamarse homosexual, palabra cuyo uso es un signo de la modernidad) o un momento de una síntesis significativa de los que marcan la transición de este período particular en Cuba. El solo hecho de haber destacado este asunto en Fresa y chocolate y que lo haya destacado el director más venerado en Cuba en un filme que atrajo la atención internacional representa un momento cultural muy significativo. En este sentido, es quizá legítimo hablar de un filme que promueve la tolerancia, ya que precisamente la década y media entre la acción de la película -justo el período anterior al éxodo de los marielitos en 1980- y los mediados de los noventa es un período en el cual Cuba vivía una transición de la insularidad relativa de una sociedad posrevolucionaria definida muy rigurosamente, con los ajustes que tenía que hacer, a la desaparición de su principal apoyo y defensa, el sistema soviético. Cuba es hoy en día apoyada por sociedades (en las que el filme ha circulado, además de los Estados Unidos) que se caracterizan por un liberalismo económico y social que no tolerarían la persecución de la libertad sexual (el filme reconoce el apoyo de las entidades fílmicas mexicanas y españolas, como también el de Robert Redford, quien ha tomado mucho interés en el industria cinematográfica cubana). Diré más sobre la importancia del período particular en que se hizo este filme, como también sobre la significación de esta distancia histórica. ${ }^{2}$

La cuestión de por qué David y Diego nunca cogen debe tratarse en dos niveles: el uno, del ennoncé, y el otro, de la énnonciation; es decir, en el nivel de la historia que cuenta el filme de Gutiérrez Alea y en el nivel de la historia que él cuenta. En ambos niveles hay problemas ideológicos que deben discutirse. Estos problemas tienen que ver con los horizontes de coherencia respecto a las prácticas sexuales al nivel de las circunstancias en que los personajes del filme están metidos y también tienen que ver con lo que la película concibe, a través del manejo estratégico de la historia de esas vidas, de las posibilidades de conectar las relaciones del mismo sexo al "hombre nuevo" posrevolucionario, una frase que aparece en el título del texto de Senel Paz sobre el cual la película está basada, El lobo, el bosque y el hombre nuevo (1991).

En el nivel de la historia que se cuenta, el filme se suscribe a una serie de suposiciones ideológicas (es decir, las reduplica) que caracterizan suposiciones fundamentales respecto

\footnotetext{
${ }^{2}$ Smith indica que Fresa y chocolate es una respuesta a Conducta impropia de Néstor Almendros. Smith llama al filme de Gutiérrez Alea una “obra de cámara” y en una forma no halagadora subtitula su ensayo "Cinema as Guided Tour".
} 
a la sexualidad y a los parámetros de las relaciones entre el mismo sexo, aun cuando satiriza muchas de éstas para forzar supuestamente una crítica que podría inducir su revisión, mientras envuelve todo maravillosamente en un sentido del humor cubano ampliamente picaresco.

El filme gira alrededor del deseo de Diego (un burócrata cultural secundario) de seducir a David (un serio estudiante universitario, aparentemente comprometido firmemente con los principios de la Juventud Comunista). Diego ha tomado algunas fotos de David en una producción de La casa de la muñeca y espera que al ofrecerle estas fotografías a Diego, el joven estudiante va a tener una relación con él (uno sospecha subsecuentemente que estas fotos no existen ya que, después de todo, David nunca las obtiene de Diego). Además Diego ha apostado con su amigo Germán, un escultor, que convencería exitosamente a David para que fuera a casa con él, donde tendría la posibilidad de conquistarlo: Diego le mostraría desde el balcón de su apartamento la camisa de David como prueba de que la misión había sido cumplida. Diego comienza a coquetear con David en la mesa de afuera de la heladería Coppelia, en el centro de La Habana. Germán los mira desde una mesa cercana. Ya que los puestos en las mesas son limitados, David, quien está solo en una mesa, la comparte con Diego, quien se apresura a llevar a cabo su plan de seducción. Un detalle adicional es la vista completa de una mesa de libros que son imposibles de obtener en Cuba (i.e. que son prohibidos en todo sentido), pero cuya lectura es extremadamente codiciada, específicamente Conversación en la catedral de Mario Vargas Llosa (1969), uno de los textos clave de la novela latinoamericana del llamado boom de los años sesenta y setenta, obra de interés por su tratamiento de un período de la dictadura militar en Perú. David muestra interés en los libros, pero se ve ansioso de recobrar las fotografías, no porque sean comprometedoras, sino porque supuestamente están en las manos de un hombre abiertamente homosexual, un maricón.

De esta manera, el filme recicla un conjunto de estereotipos latinoamericanos que eventualmente son problemáticos para el filme. El más significativo es la disyunción entre el hombre heterosexual y el homosexual extravagante. David, representado por Vladimir Cruz, es casi denodadamente heterosexual. A pesar de su cuerpo de muchacho, él está totalmente consciente de la responsabilidad heterosexista de ser hombre, con una mirada intensa y directa que no le permite dudar al otro de su cumplimiento del inventario prescrito de características en apariencia, comportamiento y lenguaje que conforman las normas patriarcales. Cuando Diego recién confronta a David, David es brusco e incluso grosero, sin dejar de transmitirle a Diego la información de que no debe haber ninguna duda de su compromiso con la heterosexualidad y de su aborrecimiento concomitante hacia la desviación sexual a la que supuestamente se adhiere al maricón y a su aparente discurso de seducción: David mira a Diego con desafío mientras mete la mano en el bolsillo de la camisa, para sacar su carné de identificación el cual indica que es miembro de la Juventud Comunista, y para luego ponerlo en el otro bolsillo de la camisa.

Bajo estas circunstancias, considerando la higiene sexual que era parte integral de la Juventud Comunista, el gesto de Diego es equivalente a mostrar un anillo de matrimonio en las propias narices del seductor: en un contexto homosexual, significa que uno no está disponible; en un contexto del mismo género, es la sugerencia de que las esposas le están 
esperando al queer ${ }^{3}$ tentador en la violencia homofóbica, la cual es la única respuesta apropiada al insistente coqueteo. David, sin embargo, sigue interesado en las fotografías que tiene Diego y por esto sigue conversando, al mismo tiempo que apenas trata de abstenerse de convertir el pedido de las fotos en una demanda amenazadora. En el punto culminante de la persecución de lo indeseable y su reclusión a la labor forzada de rehabilitación de los campos IMAP, apenas una década antes, hubiera sido suficiente que David denunciara a Diego y su intención de tocarlo inapropiadamente para que la policía se lo llevara, como explica Reynaldo Arenas en su autobiografía Antes que anochezca y como se capta en su versión fílmica de Julian Schnabel, Before Night Falls (2000). Tal vez esto sea una posibilidad en 1979, cuando la acción del filme se lleva a cabo, pero claramente no es el espíritu de Fresa y chocolate hacer una representación de la violencia homofóbica, precisamente porque Gutiérrez Alea quiere encaminar a su audiencia hacia un espíritu público en el cual ser homosexual es naturalizado, como también aseverar aunque solamente mediante una implicación- que la Cuba revolucionaria ha dejado ya la preocupación sobre la moralidad sexual pública que permitió los campos IMAP (prácticas agresivas policiales) y el derecho incuestionado/incuestionable del heterosexual de denunciar con impunidad al queer.

Para lograr esto, Fresa y chocolate implícitamente se burla de las actitudes de David y la retórica del lenguaje del filme trata de convencer a la audiencia de lo ridículo de su comportamiento: su horror fóbico de los coqueteos de Diego y de la transparencia en sus intentos de involucrarle seductivamente, la desesperación con la cual él está a la defensiva ante la posibilidad de más seducción cuando acepta ir al apartamento de Diego (incluso la manera en que lo hacen blanco de la referencia jocosa de Diego como "papito”, en el taxi colectivo después de haber llegado a casa; una mujer entre los pasajeros sigue el chiste); su alarma cuando encuentra íconos homoeróticos en el apartamento de Diego; la honestidad de su reporte sobre la experiencia de Miguel, uno de los compañeros universitarios del dormitorio, un joven (aparentemente algo como un monitor del comportamiento de los otros estudiantes), cuya honestidad también se ridiculiza en el filme. Es de particular interés la manera en que la película implica una crítica a la astucia de David cuando decide hacerse amigo de Diego, a sugerencia de Miguel, para conseguir las pruebas en contra del maricón subversivo. Este es un detalle particularmente valioso porque subraya la posibilidad de concientizar dos hechos cruciales. El primero concierne a la naturaleza repugnante de la falta de honestidad de las prácticas por las cuales el heterosexual se alista para hacer caer en la trampa al queer, creyendo que éste es tan repugnante, tan vil, tan injurioso al bienestar público que ningún intento de identificarlo y liquidarlo puede estar fuera de lo que es moral y éticamente aceptable: ante el horror del

${ }^{3}$ Uso queer en todo el texto (sin itálicas) como un sinónimo del término autoritario homosexual y del término homofóbico maricón/fag(got), ignorando, para los propósitos del momento sociohistórico del filme, la necesidad de distinguir entre queer y gay. A pesar de que los comentaristas externos han usado gay con referencia a las relaciones del mismo sexo y a la identidad en Cuba, es solo recientemente que el término ha entrado en el habla de la isla (por ejemplo, hoy aparece en los diccionarios de Paz Pérez del español cubano). Ciertamente no habría sido una palabra disponible en el vocabulario de ninguno de los personajes del filme en 1979. Por lo tanto, queer se entiende aquí como la traducción inglesa apropiada del uso cubano de las palabras maricón y puto. 
deseo por el mismo sexo y sus prácticas, ningún acto de traición puede ser tan horriblemente injusto como para ser reprochable. Así pues, cuando David subsecuentemente siente afecto por Diego, cuando hay un lazo de amistad (¿pero nunca de amor homoerótico?) entre ellos y cuando David defiende ante Miguel su relación con Diego, el repudio hacia la actitud y el comportamiento de David se reduplica de una naturaleza aun más histérica, como fue la reacción original de David hacia Diego.

El segundo asunto que tenemos aquí es la contraorden a la manera en que los queers son supuestamente arteros en su conquista de los hombres heterosexuales. Aparentemente esto es así ya que como los hombres heterosexuales poseen una sexualidad sensata y saludable, se los puede obtener solo a través del subterfugio y el engaño -tienen que ser engañados para dar su saludable hombría a la corrupción del queer. Esto parecería comprobarse en Fresa y chocolate por el hecho de que Diego trata de engañar a David para llevarlo a su cuarto (prometiéndole las fotografías y el acceso a la literatura prohibida). Él derrama, "sin querer”, café en la camisa de David para forzarle a que se la quite con el pretexto de que de esta manera podría limpiársela. Así, “lo engaña” para que revele más de su hombría de lo que la heterosexualidad sobria lo permitiría (David insiste firmemente que le dé algo para cubrirse) y con esto poder mostrarla desde el balcón a Germán como señal de que ha seducido exitosamente a David (lo cual es, a la vez, un engaño por parte de Diego, ya que ninguna seducción, como se entiende comúnmente, se ha llevado a cabo, a pesar de que esto va a verse a medida que avanza el filme). No obstante, todo esto es divertido y es un juego en comparación con la traición de la amistad que David planifica con Miguel para participar en el engaño a Diego y más efectivamente denunciarlo a las autoridades. Así pues, David regresa al apartamento de Diego, aparentemente en búsqueda de los libros prohibidos que le había prometido y para descongelar poco a poco la distancia helada que hay con Diego. La dinámica interpersonal de seguirle la corriente a Diego, dándole esperanzas falsas, requiere que David acepte el trago que Diego le ofrece (Scotch importado de los Estados Unidos, en el mercado negro). ${ }^{4}$ El filme muestra una escena en la que el patriarcal Miguel cura a David de su resaca y le advierte de los subterfugios del enemigo. Lo que hace que este salto sea una fuente de la ridiculez del comportamiento de David es que, al saltarlo, la única acción real de comportamiento homoerótico de todo el filme se lleva a cabo en esta coyuntura: los dos hombres están en ropa interior y, después de poner la cabeza de David bajo la llave de agua fría, Miguel bromeando le da una nalgada a David, exclamando que su culito está lindo y gordito. Ya que Diego nunca toca a David por su propia cuenta, este pequeño acercamiento homosexual, construido sobre el ritual del buen amigo que ayuda al otro en los momentos difíciles de una resaca, no puede sino leerse como un nuevo intento del filme de subrayar la ridiculez de la postura sobriamente heteronormativa que David trata de preservar de acuerdo con las recomendaciones de Miguel. Así pues, en el nivel de la historia que se cuenta, mientras las estrategias retóricas del filme cuestionan la supuesta heteronormatividad y, más aun, abiertamente ponen en

\footnotetext{
${ }^{4}$ En realidad, la marca es Johnnie Walker etiqueta roja, que es, por supuesto, de Escocia. Sin embargo se lo identifica como un "producto del enemigo", confirmando que es un contrabando traído desde los Estados Unidos, ya que Escocia nunca ha sido un adversario político de la revolución cubana o del gobierno de Castro.
} 
ridículo algunos de sus aspectos que se refieren a la supuesta conducta de los gays y a la legitimación de la reacción hacia ellos por parte de los que se identifican como heteronormativos (straight).

No obstante, hay también otra elaboración de la mentalidad de David que es más maliciosamente crítica que la representación de su reacción al intento de Diego de seducirlo y es la manera en la cual, aun antes de que Diego aparezca en la escena, los primeros diez minutos del filme sirven para debilitar la seguridad del machismo de David (o de su masculinidad). La película empieza con David y su novia Vivian, quienes acaban de llegar a un hotel de mala muerte donde los amantes van a resolver el problema perenne de la falta de un lugar privado en el cual puedan hacer el amor.

A pesar de que David está decidido a hacer el amor con Vivian y su deseo es estimulado por la escena en el cuarto de al lado, la cual él espía por la mirilla que descubre accidentalmente mientras Vivian va al baño, se confunde rápidamente con el comentario de ella de que todo lo que él quiere es acostarse con ella. En un gesto de nobleza, salta de la cama, recoge su ropa, y le promete "respetarle" hasta que se casen y él la pueda llevar a un hotel de cinco estrellas. La escena termina abruptamente con el rostro perplejo de Vivian y la exclamación “¡Qué!”. Esta escena se diseña para provocar la primera carcajada del público porque es obvio que el pobre David se pierde totalmente en el texto sexual que se espera que él siga, lo que resulta en que pierda su oportunidad para aseverar su machismo y, de este modo, hacer el amor con la muy gustosa Vivian, quien, después de todo, solo sigue el texto social asignado a ella de no ser sexualmente agresiva, sino virginalmente reticente.

La cámara hace un corte y luego muestra la escena del espléndido matrimonio de Vivian, bromeando con los espectadores sobre la identidad del novio. Por supuesto, vemos que no es David, y virando la cabeza altivamente en la dirección hacia él (que permanece en el fondo de la fiesta de matrimonio), ella decididamente firma el registro. Para añadir dolor al insulto, en esta caracterización de las incompetencias de David como un macho cubano paradigmático, está el hecho de que cuando subsecuentemente David y Vivian se encuentran (él parece no poder olvidarse de ella y anda por los alrededores de su casa) ella se ofrece para hacer el amor con él. Él se ofende, en el reverso del esquema machista, ya que ella lo ve solamente como un juguete sexual, y él se va muy enojado. Aún con más razón, David se siente ofendido por los coqueteos de Diego después del matrimonio de Vivian, porque ella implícitamente ha cuestionado su hombría, primero con su resentimiento por la incapacidad de desempeñarse (no por razones de ineficacia sexual, sino por un sentido equivocado de la nobleza burguesa) en el hotel y luego por su decisión de casarse con otro hombre y por lanzarle esa imagen de su decisión en la cara. No obstante, es después de desdeñar la oferta de Vivian de un devaneo sexual que David comienza significativamente a relajarse en su relación con Diego, lo cual lentamente pasa a ser afecto y una amistad auténtica. Si David da vueltas por la casa de Vivian, es tal vez porque él necesita que ella le confirme que no es gay: después de todo, una de las principales funciones sociosexuales de la mujer en la sociedad (hetero)sexista es proveer al hombre con oportunidades de afirmar su hombría, no a las mujeres sino a ellos mismos y a sus adláteres, a través del uso de la mujer como un espejo para el hombre, en la demostración infinita e inconclusa de que ellos no son queers. 
De igual manera, Diego es un estereotipo, una eficaz conjugación de diversas dimensiones de las definiciones heteronormativas del queer y de lo que se piensa que es un entendimiento no problemático acerca de la relación de éste con los hombres heterosexuales. Diego es el paradigma de la reina radiante, ya sea por sus gestos, su ropa (especialmente en privado - precisamente las prácticas agresivas de la policía en contra de los queers se concentran en el pelo largo y el vestido como signos principales de la desviación sexual), su voz/habla/lenguaje, su selección cultural y sus prioridades (su pasión por las óperas de María Callas), y especialmente, en este caso, su preferencia en la comida- el título del filme capta metafóricamente la oposición binaria heterosexista como muestra la selección de los sabores de helado en Coppelia: para los hombres el de chocolate y para las mujeres el de fresa. David, por supuesto, come el helado de chocolate, pero cuando Diego se sienta en la mesa de David, Diego no solamente saborea su helado de fresa, sino que entabla una charla exuberante en su defensa, hablando sobre una fresa suculenta que ha encontrado en su platillo como si fuera un fetiche sexual maduro. A través de esta secuencia Diego manifiesta en el pleno espacio público del patio de afuera del Coppelia que está lleno de gente, un despliegue de características asociadas con el hombre homosexual.

El comportamiento muy resuelto de Diego indica dos direcciones. En primer lugar, es una performance diseñada para clarificarle a David que está coqueteándole, pero también está dirigida a Germán, quien es el espectador específico del plan de seducción de su amigo. Sin embargo, el comportamiento de Diego es tan decidido en este punto en el cual uno sabe muy poco acerca de él o de David que uno se pregunta por qué este último simplemente no se levanta y se va cuando Diego se lanza en su rutina. Esto lleva a la posibilidad de que la performance de Diego esté dirigida tanto hacia la audiencia como, concomitantemente, hacia David y Germán: Gutiérrez Alea hace que Diego se involucre en una performance como una reina escandalosa ante la audiencia del filme como parte de una táctica para entablar una conversación para apelar a las expectativas en lo que se refiere a los homosexuales y para desafiar las suposiciones acerca de la legitimidad de esta persona sexual.

Al hacer esto, sin embargo, Gutiérrez Alea renuncia a una medida de capital semiótico y al mismo tiempo gana en otro sentido. Pierde capital semiótico al circunscribir muy estrechamente la naturaleza de la persona sexual identificada con el deseo por el mismo sexo. Al circunscribir lo homoerótico a la reina escandalosa (la cual, en su versión cubana específica está representada en el documental Mariposas en el andamio (1996) de Luis Felipe Bernaza y Margaret Gilpin) Gutiérrez Alea colabora con una práctica heteronormativa principal: la creencia por medio de la cual ser homosexual no solo significa únicamente asumir el llamado papel pasivo en el sexo, sino además manifestar el hecho (es decir, que a uno se le asigna hacer el papel pasivo) al actuar el papel de la "reina gritona" como un despliegue sobredeterminado de la "posición femenina”. Tal homología sin fisuras es menos problemática en términos de una performance manifiesta (a pesar de que no reduce el blanco de la homofobia solo a aquellos que actúan de esta manera, y asume sin necesidad de mayor evidencia que al actuar así, el individuo necesariamente se involucra en los actos no necesariamente visibles que son la razón putativa para la violencia homofóbica: ser tomado como estar actuando la desviación sexual es el equivalente incuestionable de ser 
tomado como desviado sexual, con la gama completa de atributivos horrendos). A través de esta performance se elide la entera gama de lo homoerótico: la identidad, los sentimientos, el deseo y las prácticas; individuos que puedan buscar las relaciones del mismo sexo sin actuar como reinas, a menos que ellos descuidadamente se revelen de otras maneras, permanecen libres de una violencia homofóbica que se concentra en esa performance.

La homología errónea en cuestión aquí no solo asume tal equivalencia bidireccional de la actuación como reina y desviado sexual (ser reina significa ser desviado; si uno es desviado, uno necesariamente actúa en público como reina) en lo que se supone que realmente importa (la práctica no reproductiva de actos en contra de la naturaleza), sino que ejecuta cualquier manera de describir lo que la heteronormatividad quiera denunciar como desviación sexual que no involucra la actuación como reina en público. Ésta es la “paradoja Rock Hudson” de las audacias acerca de las maneras de ser no-heterosexual. La posibilidad de ironía dramática en Fresa y chocolate, por medio de la cual Diego terminaría siendo más heterosexual que David, no es una posibilidad y, por supuesto, el filme continúa implacablemente siendo manejado por una concepción de exclusividad mutua de las categorías del deseo sexual, aun cuando lucha por la naturalización del maricón como un sujeto social legítimo en la Cuba revolucionaria. En su encuentro final (su última escena en la película) antes de la partida de Diego para aceptar la invitación de una embajada extranjera no especificada (decisión a la que es forzado porque aún y cuando David podría aceptarlo ahora, no ocurriría lo mismo con el sistema revolucionario y él sería despedido de su posición como burócrata cultural) David está radiante por la realización de su encuentro sexual con una mujer, mientras Diego imita la náusea que el pensamiento sobre el sexo le puede dar a un maricón totalmente comprometido como el que él se enorgullece en ser.

La mímica de náusea por parte de Diego en el nivel de la historia que se nos cuenta es, ciertamente, otro gesto de Gutiérrez Alea, en el nivel del filme como texto cultural, hacia una audiencia que también tiene esa creencia acerca de los hombres queer, lo cual a la vez debe provocar su propia forma de náusea en el hombre heterosexual por el rechazo abierto al placer del sexo con una mujer y su implicada preferencia por el sexo con otro hombre: la representación de la relación entre Diego y David a la vez abre y cierra con apelaciones a los horizontes de conocimiento de la audiencia respecto a la preferencia sexual.

Sin embargo, si Fresa y chocolate invierte en Diego una gama compacta de estereotipos sobre el queer, es importante, no obstante, comentar en la presencia corporal relativa entre David y Diego. Si bien David en ningún momento traiciona ninguna de las señales abiertas que lo harían sospechoso desde el punto de vista del mantenimiento de la higiene sexual -es decir, en ningún momento él está en peligro de causar un bip en la pantalla del radar de la homofobia- y, por otra parte, Diego lucha por una perfecta performance de la reina homosexual, es interesante acotar que el cuerpo de Diego es más masculino que el de David. Jorge Perugorría (el actor que representa el papel de Diego) tiene un cuerpo musculoso y velludo que le da ventaja; este cuerpo es particularmente bien utilizado por Perugorría en películas subsecuentes a Fresa y chocolate, en las cuales el despliegue hipermasculino de sus personajes, con la sinergia de su físico, es particularmente 
evidente (como que si afirmara que él, el actor, a pesar de su papel en Fresa, es incuestionablemente heterosexual: una posibilidad altamente irónica en términos de la “paradoja Rock Hudson" antes mencionada, por medio de la cual mientras más insistente es la exhibición de la masculinidad heteronormativa, más grande es la latitud de suponer una postura irónica hacia la heterosexualidad obligatoria). Además, debe notarse que la exhibición del cuerpo masculino es tradicionalmente más legítima en Cuba (y otras sociedades latinoamericanas, pero no todas: Argentina y México, por ejemplo, serían excepciones) que en los Estados Unidos.

Lo anterior es una generalización difícil por los muchos cambios en la sociedad americana directamente relacionados por un lado con la cultura queer y por otro, con la gran informalidad del vestir público en las generaciones recientes. Sin embargo, la tal llamada imagen clon gay en la sociedad norteamericana coincide de muchas maneras con la forma de despliegue masculino que no es necesariamente marcado en la sociedad cubana, como se puede apreciar en la masculinidad bien desplegada del personaje de Perugorría en, por ejemplo, su próximo filme, Guantanamera (1994) de Gutiérrez Alea (en el cual la actriz principal está representada por Mirta Ibarra, la vecina y hermana espiritual de Diego, la comerciante al por menor en el mercado negro Nancy que trata de suicidarse algunas veces en Fresa y chocolate). He escrito anteriormente acerca del uso efectivo del despliegue del cuerpo masculino con referencia al filme brasileño, Jorge um brasileiro (1988) de Paulo Thiago. Jorge también es un personaje heterosexual, dotado icónicamente de todas las características socialmente redentoras asociadas con el imperativo heteronormativo, por medio del cual ser heterosexual significa contribuir a la reproducción de ciudadanos para el Estado y reafirmar una serie de virtudes de hombre que sostienen su propio funcionamiento. La cuestión es que la presencia monumental de Diego ocupa el espacio tomado por el hombre heterosexual imponente, como se presenta en Guantanamera (donde él es, de hecho, un redentor social) haciendo de pronto ambiguo ese espacio.

Además, Diego es verdaderamente muy guapo, casi bonito, con ojos oscuros penetrantes, pestañas abundantes y piel suave y bien mantenida, características que son tradicionalmente sospechosas en el hombre norteamericano (históricamente en los Estados Unidos, un hombre no debe ser tan guapo), ${ }^{5}$ pero no en el conjunto de características valoradas por el macho latino. Finalmente, lo que es más impresionante acerca de la belleza física de Diego, aparte de la ambigüedad que ésta pueda provocar en la clasificación

\footnotetext{
${ }^{5}$ Debo reconocer que en español también existe la creencia en este sentido, como se ve en el dicho "El hombre es como el oso: cuanto más feo, más hermoso". Sin embargo, la cuestión es que ser hombre y guapo no presiona los límites de la aceptabilidad heteronormativa en la cultura hispana como sucede tradicionalmente en la cultura norteamericana. Concomitantemente, debe notarse el hecho de que Hollywood, mientras atesora los íconos masculinos americanos simples (Van Johnson, Gary Stewart, Ronald Reagan, Rock Hudson) también ha permitido la belleza masculina, sin confundirla necesariamente con la homosexualidad, aún cuando muchas de estas bellezas masculinas de Hollywood sí hayan tenido una dimensión queer en sus vidas: Montgomery Clift, Cary Grant, Marlon Brando, César Romero. Romero, por supuesto, trabajó para Hollywood como el ícono del amante latino. Véase Meyer en su discusión sobre el cuerpo de Hudson; véase Hadleigh sobre varias de las estrellas masculinas de Hollywood arriba mencionadas.
} 
entre los hombres heterosexuales y los queers es el hecho de que, al lado de David, Diego es un hombre más imponente. No es que David sea afeminado o desairado (a menudo también considerado como un signo de afeminamiento), sino que simplemente el cuerpo muscular de Diego ensombrece el de David, a menudo casi escuálido. El cuerpo de Vladimir Cruz, como se ve en un filme cubano reciente Un paraíso bajo las estrellas (1999) de Eduardo Chijona, es mucho más lleno y muscular, sin necesariamente llegar a ser el mesomorfo que es Perugorría, lo que le conduce a uno a preguntarse si Cruz es deliberadamente creado en Fresa y chocolate para tener una apariencia más escuálida junto a Perugorría. ${ }^{6}$

Sean ciertas o no estas consideraciones, el simple hecho es que la presencia física de Perugorría es monumental, lo que subraya y debilita el papel de reina de su personaje Diego. Lo subraya porque ese papel de reina es incongruente con su presencia hipermasculina y lo debilita porque rompe el estereotipo del hombre gay menudo. Consideren, por ejemplo, qué efecto habría tenido hacer que el papel de Diego lo representara Joel Angelino (Angelino representa el papel del amigo escultor de Diego, cuyo trabajo le causa problemas con sus superiores en la oficina cultural en la que trabaja). El menudo y pelirrojo Angelino, con un cuerpo suave que no se compara con la estructura muscular de Perugorría o con la estructura fuerte de Cruz, simplemente habría alimentado los estereotipos de la audiencia respecto al hombre gay que incluso habría invitado a un completo rechazo. Así pues, mientras Gutiérrez Alea reproduce estereotipos para cuestionar su validez, sus personajes articulan elementos de violencia homofóbica al nivel de la historia que se cuenta para cuestionar en el nivel de la retórica la legitimidad de esa violencia (la cual, repito, se mantiene esencialmente verbal en el filme). Al mismo tiempo, su filme evita reproducir estereotipos presentando un actor que es a la vez reina y un monumento de hombre, una contradicción que es claramente visible cuando se hace referencia a Germán que es completamente estereotípico.

También hay problemas retóricos e ideológicos entre el nivel del ennoncé y de énnonciation. Una de las características principales del filme es la virginidad de David, la cual se cruza con su suscripción a una severa heteronormatividad. No es que lo uno sea una consecuencia de lo otro (la heteronormatividad, en Latinoamérica, puede que no excluya el sexo antes del matrimonio tan categóricamente como sucede a menudo en Estados Unidos), sino que, precisamente, David tiene aun una mejor razón para alarmarse por los coqueteos de Diego: al mismo tiempo que él fracasa con las mujeres, es coqueteado por los hombres. En el nivel de la historia que se cuenta, Diego le ha hecho el gran favor a David de arreglar la situación para que pueda hacer el amor. Esto lo logra persuadiendo a su vecina Nancy de que se acueste con David (Nancy tiene una razón para ser simpática con David ya que él dona sangre una vez cuando ella trata de suicidarse cortándose las venas), y él cuidadosamente arregla todo; Diego los deja solos en su apartamento y Nancy y David hacen el amor en la cama de Diego. David está, subsecuentemente, eufórico y no se molesta con Diego cuando éste le dice que fue él quien arregló todo este asunto, y los dos bromean acerca del hecho de que esto haya ocurrido precisamente en la cama de Diego.

\footnotetext{
${ }^{6}$ Perugorría habla de actuar "este gran papel” en su entrevista con Kirk y Pardura Fuentes (171). Véase también la entrevista con Birringer.
} 
Posteriormente David anuncia sus intenciones de casarse con Nancy. Este anuncio ocurre en el mismo momento en que se despiden, ya que Diego se prepara a salir del país para trabajar en una embajada extranjera.

Ahora, hay muchos asuntos curiosos que surgen en la trama que deben revisarse desde el nivel de la retórica del filme: el hecho de que David finalmente haya tenido una aventura sexual, pero con Nancy; el hecho de que hagan el amor en la cama de Diego; y el hecho de que David no se moleste de que esto haya sido la consecuencia de las maquinaciones de Diego en vez de ser el resultado de sus conquistas con las mujeres. Lo que me gustaría proponer es que mientras David hace el amor con Nancy y mientras el encuentro es (en aparencia) totalmente satisfactorio con consecuencias duraderas que pueden resumirse bajo el término “amor”, al mismo tiempo David en un sentido muy real ha hecho el amor con Diego. Es importante notar que el único contacto realmente físico entre los dos hombres ocurre después de que David y Nancy han hecho el amor: en el apartamento, ahora desmantelado de Diego, David es capaz de intercambiar un abrazo cálido, tierno y largo con Diego. Por supuesto, es una señal del grado de amistad que ha surgido entre ellos y, por supuesto, es un gesto sincero de despedida que David expresa a Diego ya que sabe que este, después de todo, tiene que abandonar la Cuba con la cual él se identifica tan profundamente (le había asegurado a David, desde el principio de su relación, que él no tenía ninguna intención de abandonar Cuba, aun cuando tocaba para David “Adiós a Cuba”, el baile evocador de piano de Ignacio Cervantes). Por supuesto, el abrazo es una señal de cuánto ha aceptado la naturalidad del hecho de que Diego es gay. Por supuesto, también es cierto que ahora David puede permitirse abrazar a Diego, ya que él puede pensar que la cita con Nancy ha asegurado incuestionablemente su estado de heterosexista.

David subraya su aceptación de Diego cuando le cambia el helado en la reunión de despedida en el Coppelia, cuando él no solo le da el helado de chocolate que es para hombres, sino que procede a escarbar en el helado de fresa de Diego imitando la manera en que Diego imitaba el discurso de la reina, hasta el saboreo de la fresa fetiche y regordeta. Nada de esto significa que David de pronto se haya vuelto gay -como sucede con el personaje de Cary Grant en Bringing Up Baby (1938). Lo que sí queda claro es que hay una sintonía entre los dos hombres (manifestada incluso públicamente) que va más allá de la mera "aceptación" de las diferencias del otro. Desde este punto de vista, uno podría especular sobre el hecho de que David y Diego se acuestan “a través de” Nancy -y en la cama de Diego. Es un lugar común afirmar que uno nunca está haciendo el amor sólo con la persona involucrada en el acto sexual, sino con todas las personas que constituyen nuestra historia sexual y nuestras fantasías (un asunto que se ve claramente en la escena inicial de la obra de teatro de Paul Rudnick, Jeffrey [1994], con versión cinematográfica de 1995, dirigida por Christopher Ashley). Es igualmente un lugar común sostener que las mujeres, en una sociedad homofóbica, homosocial y sexista (cada adjetivo implica el otro), son puentes entre una relación que realmente está llevándose a cabo entre hombres (de esto se trata, por ejemplo, en la sexualidad reprimida en O beijo no asfalto [1981] del brasileño Bruno Barreto, donde la mujer sin saberlo es el lazo erótico entre su padre y su marido). ${ }^{7}$

\footnotetext{
7 Véase Foster, Gender 129-38.
} 
La proposición de que los hombres, en el contexto de un heterosexismo hegemónico, ya que no pueden coger entre ellos, deben desplazar su atracción y expresarla a través de otros medios, a menudo a través de las mujeres, quienes los acercan y los mantienen en un lazo que se espera que sea duradero (como la relación entre el suegro y el yerno en el filme de Barreto), se explora ampliamente en el estudio sobre la larga relación entre los personajes de los shows (road shows) que Bing Crosby y Bob Hope hicieron juntos. En estos shows, por ejemplo, Dorothy Lamore (y otras mujeres), constituye un puente entre los dos hombres, un dúo cuasi/pseudo-erótico, no realmente serio, cuya interacción es aumentada respecto a los chistes de insinuación sexual donde una carcajada sirve para remplazar, en el espectador, el momento de reflexión sobre lo que, después de todo, podría estar pasando entre los dos hombres. El personaje de Marilyn Monroe cumple la misma función en la relación entre los personajes de Tony Curtis y de Jack Lemon en Some like it Hot (1959) de Billy Wilder. ${ }^{8}$ Por supuesto, Sugar Cane siempre se está quejando de cómo, con los hombres, siempre tiene el lado velloso del chupete (una imagen básicamente sin sentido, excepto tal vez como una metáfora lesbiana), y la mujer que Jack Lemon representa, Daphne, es un puente entre él y Osgood Fielding III de Joe E. Brown, a quien realmente no le importa (ya que "nadie es perfecto") que un hombre esté en el otro lado de la mujer. En Fresa y chocolate, lo que realmente es divertidísimo es que mientras Cruz saborea la fresa de la femineidad, Diego le dice que lo único malo de él es que no es maricón. En ese instante David mira a Diego a los ojos y le dice; “Nadie es perfecto”. Todo este jugueteo en la relación entre Diego y David trae problemas a David con Miguel por defender a Diego: David termina siendo asaltado verbalmente por su compañero, quien le acusa de llevar flores a su amante masculino (las flores son para Nancy); Miguel sale gritándoles a los dos “maricones”. Esto va más allá de "amar al pecador, pero no al pecado”, lo cual es la postura convencional de la tolerancia heterosexual liberal hacia el queer: uno debe expresar afecto por este último, pero hay la necesidad constante de reforzar el mensaje de que cualquier cosa que se toma como una apertura hacia la satisfacción del deseo homoerótico está estrictamente prohibida. La necesidad de poner límites constantemente entre los dos siempre asume que hay un punto claro donde la inauguración del programa homoerótico ha empezado a llevarse a cabo, pero ciertamente esto no se puede determinar con facilidad: ¿empieza con un beso?, ¿es el momento inesperado de tocarse tiernamente?, ¿es la repentina mirada larga con la cual David bendice a Diego mientras pronuncia una de las más famosas frases de la cultura gay contemporánea? El hecho de que Cruz, de quien no se espera que esté familiarizado con los íconos culturales de los años cincuenta de la población gay de los Estados Unidos, los sepa en 1979, cuando los filmes estadounidenses difícilmente podrían haber sido el orden del día, refuerza cómo Gutiérrez Alea está jugando con la mezcla de lo que es coherente en el nivel de la historia del filme y lo que es coherente en el nivel de su retórica: Cruz habla al nivel de los espectadores cubanos a principios de la década del noventa, quienes podían haber visto el filme de Wilder o, con la llegada de la cultura gay a Cuba a principios de los ochenta, haber oído la frase, tal vez sin saber su origen.

\footnotetext{
${ }^{8}$ Véase Foster, "Some Like it Hot".
} 
Así pues, David y Diego de cierta manera sí cogen. ${ }^{9}$ Cruz no sólo se hace el amigo profundamente leal de Diego, aun sufriendo una confrontación con el despiadado Miguel cuando trataba de defenderlo, sino que entra de una manera significativa en el mundo de Diego y, más importante, en el entendimiento de lo que constituye un deseo erótico, comprendiendo de este modo el sufrimiento de los individuos que no sólo ven la satisfacción de su deseo insistentemente negada (al lado de lo cual es trivial la postergación de la primera aventura sexual de David), sino que además son brutalmente abusados por esto, tanto verbal como físicamente. David nunca tiene relaciones sexuales con Diego de la manera en que se entiende tener relaciones sexuales, a pesar de que yo insisto en que la manera en que están juntos en la última tercera parte del filme sí constituye una versión del erotismo del mismo sexo, aunque sólo sea “a pasos de bebé”. No obstante David actúa su propia sexualidad para Diego.

En términos voyeuristas, el macho siempre se jacta de sus conquistas ante otros hombres (a menudo ante otras mujeres, pero más para seducirlas: la heterosexualidad constantemente debe ser actuada y reactuada), pero se hace con el espíritu de (re)conformar la masculinidad heteronormativa para beneficio y aprobación de otros heterosexuales, no como parte de la consolidación de la amistad con un hombre gay. Diego desaparecerá del mundo de David, al menos desde la perspectiva del año 1979, pero es claro que él permanecerá en la conciencia de David, y como algo mucho más que un amigo gay a quien David ha aprendido a tolerar. Así pues, Gutiérrez Alea, de una manera muy vacilante que no está libre de algunos problemas ideológicos significativos (por ejemplo, ¿dónde deja todo esto a Nancy, corazón de oro?) permite que David y Diego alcancen un nivel de intimidad que es mucho más que la de "buenos amigos”, y al mismo tiempo que evita aunque sólo levemente- los sitúa en el compromiso completamente homoerótico que se considera ahora imperativo (y lo ha sido, desde los años ochenta por lo menos) por haber confirmado la naturalización y la legitimidad del amor entre personas del mismo sexo.

Traducido por Cecilia Mafla-Bustamante.

\footnotetext{
${ }^{9}$ Considero lo siguiente: "In an interview that I conducted with Senel Paz about Strawberry and Chocolate, he spoke to this issue [i.e., a sexual relationship between David and Diego], saying that if David had been a repressed homosexual (i.e., if Diego had managed to draw David out of a repressed homosexuality), the film would have been weakened because the intention was to portray a heterosexual character who had the capacity to understand a homosexual and his situation in Cuban society” (Bejel 70). No niego la intención del escritor del guion ni la del director, ni tampoco niego el hecho de que se habría debilitado la intención si hubiera habido una relación sexual entre Diego y David; es solamente que los significados excedentes de un texto nunca permiten un éxito rotundo en la ejecución de las intenciones autoriales.
} 
Aldrich, Robert. The Seduction of the Mediterranean; Writing, Art and Homosexual Fantasy. London: Routledge, 1993.

Anderson, Benedict. Imagined Communities. Reflections on the Origen and Spread of Nationalism. London/New York: Verso, 1991.

Arenas, Reinaldo. Antes que anochezca: autobiografía. Barcelona: Tusquets, 1992.

Before Night Falls. Dir. Julian Schnabel. New York: Fine Line Features-Grandview Pictures, 2000.

Behar, Ruth. “Queer Times in Cuba”. Bridges to Cuba. Puentes a Cuba. Ruth Behar, ed. Ann Arbor: University of Michigan Press, 1995. 394-415.

Bejel, Emilio. "Strawberry and Chocolate Coming Out of the Cuban Closet". South Atlantic Quarterly 96/1 (Durham, 1997): 65-82. Also as "Fresa y chocolate o la salida de la guarida; hacia una teoría del sujeto homosexual en Cuba”. Casa de las Américas 196 (La Habana, 1994): 10-22.

Birringer, Johannes. "Homosexuality and the Revolution; An Interview with Jorge Perugorría”. Cineaste 21/1-2 (New York, 1995): 21-2.

Foster, David William. Gender and Society in Contemporary Brazilian Cinema. Austin: University of Texas Press, 1999.

"Some Like It Hot, Some Like It Queer." unpublished.

Jorge um brasileiro. Dir. Paulo Thiago. São Paulo: Transvideo, 1988.

Fresa y chocolate. Dir. Tomás Gutiérrez Alea y Juan Carlos Tabío. Script: Senel Paz. I.C.A.I.C., 1993.

Hadleigh, Boze. The Lavander Screen: The Gay and Lesbian Films: Their Stars, Makers, Character, and Critics. Secaucus, NJ: Carol Publishing Group, 1993. Hollywood and Whine: The Snippy, Snotty, and Scandalous Things Stars Say About Each Other. Secaucus, NJ: Carol Publishing Group, 1998.

Kirk, John M. y Leonardo Padura Fuentes. “Jorge Perugorría: Climbing Up a Mango Tree”. Culture and the Cuban Revolution; Conversations in Havana. Gainesville: University Press of Florida, 2001. 167-76.

Leiner, Marvin. Sexual Politics in Cuba; Machismo, Homosexuality, and AIDS. Boulder: Westview Press, 1994.

Lumsden, Ian. Machos, Maricones, and Gays; Cuba and Homosexuality. Philadephia: Temple University Press, 1996.

Mariposas en el andamio. Dir. Margaret Gilpin y Luis Felipe Bernaza. Cuba: Kangaroo Productions-Water Beaver Films, 1996.

Meyer, Richard. “Rock Hudson’s Body”. Insdide/Out; Lesbian Theories, Gay Theories. Diana Fuss, ed. New York: Routledge, 1991. 259-88.

Paz, Senel. El lobo, el bosque y el hombre nuevo. México: Era, 1991.

Paz Pérez, Carlos. Diccionario cubano de habla popular y vulgar. Madrid: Agualarga, 1998.

La sexualidad en el habla cubana. Madrid: Agualarga, 1998. 
Quiroga, José. Tropics of Desire; Interventions from Queer Latino America. New York: New York University Press, 2000.

Román, David. “Tropical Fruit”. Tropicalizations; Transcultural Representations of Latinidad. Frances R. Aparicio y Susana Chávez-Silverman, eds. Hanover: Darmouth College/University Press of New England, 1997. 119-35.

Santí, Enrico Mario. “Fresa y chocolate: The Rhetoric of Cuban Reconciliation”. MLN; Modern Language Notes 113/2 (Baltimore, 1998): 407-25.

Serna Servín, Juan Antonio. “An Ideological Study of the Film Strawberry and Chocolate”. Anuario de cine y literatura en español 3 (Villanova, PA, 1997): 159-66.

Smith, Paul Julian. "Cuban Homosexualities: On the Beach with Néstor Almendros and Reinaldo Arenas”. Hispanisms and Homosexualities. Durham: Duke University Press, 1998. 248-68. Orig. in his Vision Machines; Cinema, Literature and Sexuality in Spain and Cuba, 1983-93. London: Verso, 1996.

"Fresa y chocolate (Strawberry and Chocolate): Cinema as Guided Tour”. Vision Machines; Cinema, Literature and Sexuality in Spain and Cuba, 1983-93. London: Verso, 1996. 81-98.

Un paraíso bajo las estrellas. Dir. Gerardo Chijano. La Habana: ICAIC-TVE-Nirvana, 1999. 